\title{
Application of positive matrix factorization and pollutants tracing for identification of dust sources: A case study in Khuzestan, Iran
}

\author{
Zahra Akbari ${ }^{1}$, Omidreza Kakuee ${ }^{1^{\dagger}}$, Reza Shahbazi ${ }^{2}$, Javad Darvishi Khatooni ${ }^{3}$, Mahdi Mashal $^{3}$ \\ ${ }^{1}$ Physics \& Accelerators Research School, Nuclear Science and Technology Research Institute, 14395-836 Tehran, Iran \\ ${ }^{2}$ Director Management of Geohazards, Engineering and Environmental Geology, Tehran, Iran \\ ${ }^{3}$ Ceological Survey of Iran, Southwestern Area (Ahvaz Center), Ahvaz, Iran
}

\begin{abstract}
In this study for identification of internal and external origins of dust events in the southwest of Iran, for the first time, a comprehensive dust sampling was performed in nine regions of Khuzestan over the four seasons. The dust samples were analyzed using INAA nuclear technique. Factors obtained from applying the PMF Modeling indicated five kinds of pollutant sources which include 1) Sedimentary surface soil/dried bed of wetlands, 2) steel and metalworking industries, 3) refineries, 4) waste, and 5) solid fuel as well as oil fuel power plants. These identified sources were used as the tracers to identify the internal dust sources. Investigation of NASA AOT images and the synoptic data at the event dates showed that in the period of mid-autumn up to the early winter, dust events had external origins, that are mainly situated in Iraq and Saudi Arabia, while in the period of mid-summer to early autumn and mid-winter up to the early spring, the internal sources such as mud-salt zones or areas with fine sediments with evaporitic deposits and puffy grounds in the regions between Omidieh - Mahshahr, south, and southeast of Ahvaz, "Dasht-E-Azadegan," and dried bed of Hoor-Al-Azim are more dominant.
\end{abstract}

Keywords: Dust, INAA, Khuzestan, PMF, Pollutants, Source Identification

\section{Introduction}

Khuzestan province is an oil-rich region in the southwest of Iran. There are many oil, metal, and other industries in this province. Therefore, there are various artificial pollutant sources in this region. Moreover, dried lands and wetlands throughout this province are the different sources prone to make dust events. In addition to internal sources, extensive desert areas in the neighboring countries such as Iraq and Saudi Arabia are the primary foreign sources of dust events. Fig. 1 shows a list of primary sources of pollutants distributed throughout the areas of this study in the province. Fig. 2 offers the types of soil zoning of this province. As can be seen in this figure, large areas of the province are covered in clay and silt soil. This type of soil is skillful of arising from the surface in the atmospheric currents. Several research groups have investigated dust storms, their origin, and their adverse impacts on human health in recent years [1-11]. Many studies have been completed or are being carried out in the Middle East, where there are large desert areas prone to rising dust, and this problem has always been one of the most challenging topics [1, 3, 6, 12-14]. These areas cover vast deserts from North Africa to Iran and neighboring countries like Saudi Arabia, Iraq, and Syria. In most of the research conducted in each of these countries, external and internal dust sources have been considered. In Iran, a lot of studies have been done during the last decades on this ecological problem $[1,4,5,8,9,11]$; most of which were limited to and focused on a single region such as Ahvaz or other cities of Khuzestan. To our knowledge, no comprehensive study has yet been undertaken in which the entire province was simultaneously investigated during all seasons of the year. In recent five years, a team of the National Dust Committee has conducted a wide range of studies covering various types of samples for the first time including geological, biological, and atmospheric samples. In this research work, the complete set of dust samples collected by the above team from across the province are employed.

To identify internal dust sources, recognition of primary pollutant sources around the sampling locations is essential. Pollution particles due to the pollutant sources in the study area will settle
This is an Open Access article distributed under the terms of the Creative Commons Attribution Non-Commercial License (http://creativecommons.org/licenses/by-nc/3.0/) which permits unrestricted non-commercial use, distribution, and reproduction in any medium, provided the original work is properly cited.

Copyright (C) 2022 Korean Society of Environmental Engineers
Received August 02, 2021 Accepted November 15, 2021

${ }^{\dagger}$ Corresponding author

E-mail: okakuee@aeoi.org.ir

Tel: +0098 (0)21 88221103 Fax: +0098 (0)21 88221113

ORCID: 0000-0002-6728-308X 


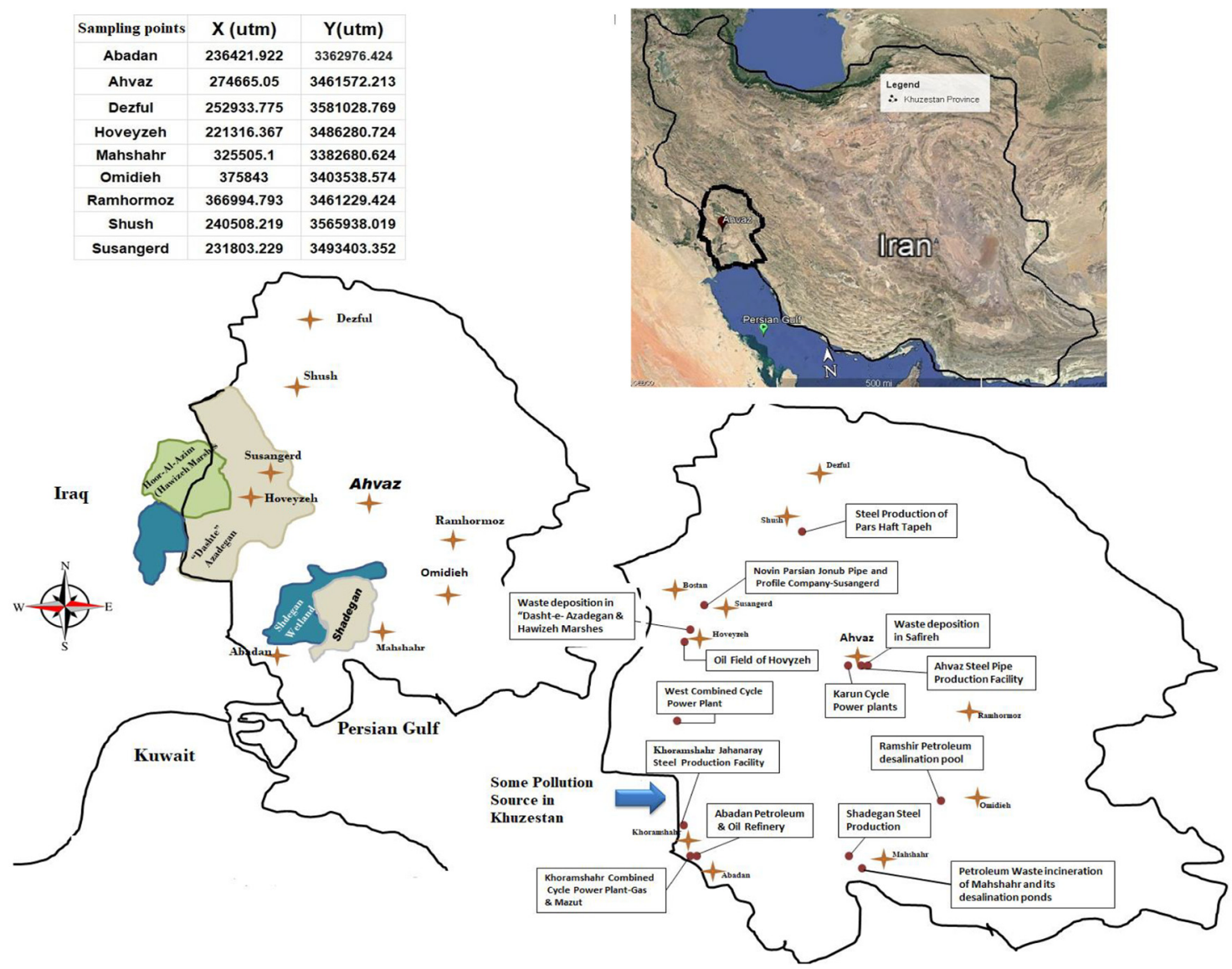

Fig. 1. Dust sampling locations and main pollutant centers in Khuzestan province.

on the surface soil over time, and their amount will increase over the years. When the soil of these areas is exposed to atmospheric currents, it will rise from the surface in the form of dust and move with the wind currents. For areas covered with clay and silt, as mentioned, the ability of the soil to rise from the surface will be much stronger. Therefore, if dust sampling is performed in such areas, indubitably strong traces of the mentioned pollutant sources will be detected in the samples. In other words, these pollutant sources could well indicate that the dust most probably has been originated from the local areas.

In this study, we try to find the probable internal and external sources of dust in Khuzestan province; therefore, applying the PMF Modeling on the elemental concentrations of dust samples collected from across the areas covered with clay and silt soil will lead to obtaining some factors that indicate pollutant sources. Tracing these sources of pollution will lead us to identify the internal sources of dust in the study area. Investigation of NASA AOT images and synoptic data at the sampling sites will help us to identify probable foreign sources. Moreover, to confirm the PMF Modeling results, we will calculate the correlation coefficients and EF (Enrichment Factor) for chemical elements in the dust samples and investigate the elements with significant $\mathrm{EF}$ values and the elements with strong correlations in each sample that are indicators for pollutant sources.

\section{Materials and Method}

\subsection{Sample Collection and Chemical Analysis}

The dust sampling practically was started in August-2018. The strategy for the selection of dust sampling periods was to cover all the seasons, especially autumn, winter, and spring; based on the previous experiences, dust events with internal and external origins are more likely to happen in these seasons. The strategy for selection of sampling locations was to cover all the zoning areas in Fig. 2. However, because of some technical problems and natural limitations such as rainy days or no events in some locations during the sampling period, the collected samples were not enough in some areas and time intervals. Sampling was scheduled to be completed in the winter of 2020, but for Ahvaz city, there was no acceptable sample due to the above-mentioned reasons. Therefore, for this city, the sampling was extended to April 2020. Nevertheless, in contrast to the previous years, there was no noticeable dust event during the spring season. This is why we do not have enough samples from the spring season. In total, the most acceptable collected samples for this study were Abadan samples, which were collected in three time intervals, including samples collected over the periods of August-2018 to September-2018, September to October-2018, and finally December-2018 to 


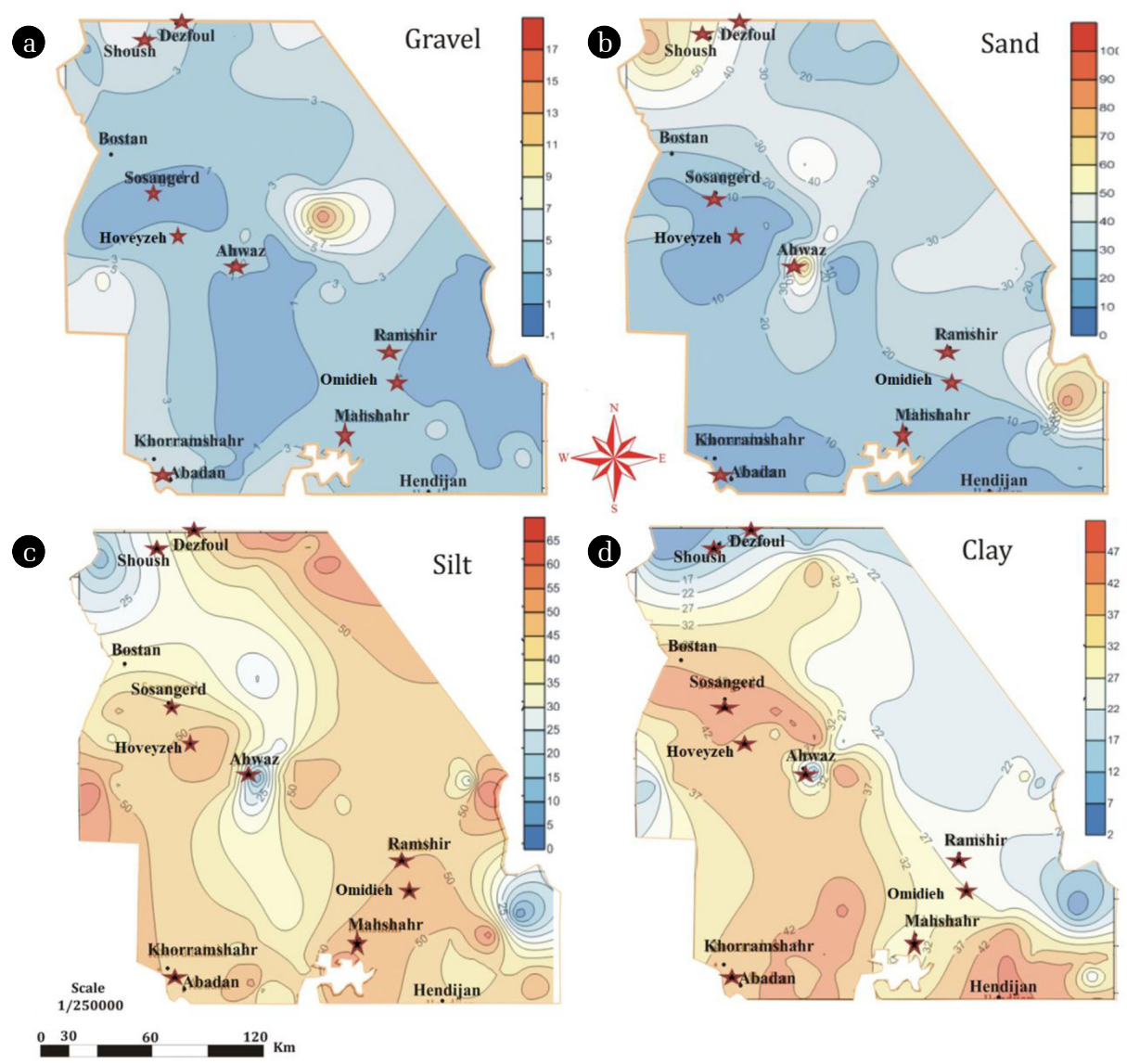

Fig. 2. Zoning of sediment distribution in Khuzestan plain, according to the frequency of constituent particles. All dust sampling cities are mentioned in the area with star marks including Dezful, Shush, Hoveyzeh, Susangerd, Abadan, Mahshahr, Omidieh, Ramhormoz (or Ramshir) and, Ahvaz.

January-2019, each one for one month. Dust sampling in Hoveyzeh, Shush, Dezful, Susangerd, Mahshahr, Omidieh, and Ramhormoz was performed over one week in February-2020. The sample of Ahvaz city was also collected in April 2020 over one week. Fig. 1 refers to the locations of the sampling areas.

As there were no disturbing buildings around, samples of Omidieh, Susangerd, Hoveyzeh, Shush, and Ahvaz were collected in the open area on the ground. However, samples of Mahshahr, Dezful, and Ramhormoz were collected at the roof of the office buildings. The sample collection container was an open glass box of square cross-section $1 \times 1 \mathrm{~m}^{2}$ with $25 \mathrm{~cm}$ edges, while a plastic net was used on the bottom of the container to collect the dust. The particles of the collected dust samples generally had a diameter of less than $6 \mu \mathrm{m}$, i.e., the silt soil granulation, and most of them had a diameter of less than $4 \mu \mathrm{m}$, i.e., the clay granulation. The Instrumental Neutron Activation Analysis (INAA) [14, 15] was applied for the elemental analysis of dust samples. This technique is very potent and non-destructive. At the same time, it is very accurate compared to other elemental analysis techniques and covers a wide range of chemical elements. Another advantage of this method is that only a small sample size is sufficient for the analysis. A maximum amount of $250 \mathrm{mg}$ of samples was used in this work.
It should be mentioned that parallel to the dust samples, the corresponding standard samples of IAEA-SOIL-7, IAEA-SOIL-5, and Coal-1632a were also irradiated and used for the analysis. Neutron irradiation of the samples was conducted using the irradiation rabbit of the Tehran Research Reactor at the power of $4 \mathrm{MW}$ (Megawatt). Samples were measured by the gamma-ray spectroscopy system and the collected spectra were analyzed using SPAN analysis software. The analysis results were outlined as the identified chemical elements in the samples and their concentrations in ppm [16, 17]. The obtained results are reported in Table S1.

After extracting the chemical composition of the samples and their concentrations, enrichment factors calculation, correlation coefficient calculation, and PMF Modeling were used to identify the sources of contaminants in the samples. Subsequently, by considering the atmospheric data of the province and nearby regions, the internal dust source areas were identified.

\subsection{PMF Modeling}

PMF (Positive Matrix Factorization) modeling is a computational approach for quantifying the share of sources in the samples based on the composition or fingerprint of the sources. In the modeling, some key elements or compounds are needed to distinguish the 
different effects of sources. A special set of data is considered as an $\mathrm{X}$ matrix with dimensions $\mathrm{i}$ and $\mathrm{j}$, where $\mathrm{i}$ is the number of the samples and $\mathrm{j}$ is the number of the chemical elements. The purpose of this model is to solve the chemical mass balance $(\mathrm{CMB})$ in Eq. (1) between the concentrations of the measured elements and the profiles of the sources, where $p$ is the number of factors, $\mathrm{f}$ is the element profile of each source, and $\mathrm{g}$ is the mass of each factor in each sample.

$$
X_{i j}=\sum_{k=1}^{p} g_{i k} f_{k j}+e_{i j}
$$

eij is "remaining" for each element/sample. In fact, PMF is a factor analysis tool that separates a data matrix of a sample into two matrices, which include the factor share matrix $(G)$ and the factor profile $(\mathrm{F})$. These factor profiles are interpreted by the individual to identify the type of sources that may have a contribution to the sample using the source profile information, emissions, and discharge rates (enrichment or depletion of the source effect in each sample).

In this study, the EPA-PMF 5.0 software was used for the modeling [18]. The software input data are the same concentrations measured by the INAA technique [16]. Table S2 presents the classified elements according to some characteristics such as $\mathrm{S} / \mathrm{N}$, i.e., signal to noise ratio of measured elements concentrations in the samples and their correlation with other elements in the modeling. The stronger elements that are stronger are called Strong. Some are relatively weaker and are in the Weak category, and some whose specifications are not good are in a Bad category and have been removed from the modeling. Other information in this table includes the lowest concentration of elements in the measured samples, the highest value, its average, $25 \%$ and $75 \%$ of the concentrations. In our modeling, the element $\mathrm{U}$ did not have a good correlation and was therefore excluded from the modeling.

After this step, the Base Run (BR) is performed with the proposed numbers for initial factors and run number. In this program, the number of runs was set to 100 to get a high accuracy. We started with the highest proposed factor number, and the most appropriate number, " 5 " was finally selected. In fact, this number is based on the basic information, such as how many sources could have affected the samples. The optimal factors ultimately have lower BS (Bootstrap) and DISP (Displacement) errors for their elements. BS and DISP are related to the statistical error and the amount of deviation of the factors from the actual factors, respectively. In this study, for the optimum run (run 1) among 100 runs, elements in each factor according to the value of adaptation in the factor have an order of BS and DIS value. For those with the highest adaptation, errors were lower, and vice versa. For run number"1," the adaptations of all elements in factors were higher than $85 \%$ that is a good result for the modeling.

After applying the PMF model on the elemental concentrations, some factors were produced contained the correlated elements. Fig. 3 indicates the results of the final implementation of PMF modeling. Each number represents the percentage of element present in the relevant factor. It is assumed that only the elements with a large share in the factor construct the factor, and the other elements with a low share are usually due to the interference of other factors.

\subsection{Enrichment Factor Calculation}

The quantity that is commonly used to study the level of enrichment of elements in geological and environmental samples is known as the enrichment factor [19]. This factor indicates the amount of change in the concentration of elements. The changes are mainly due to the effect of human resources. The enrichment factor is defined by the following formula [20].

$$
\text { Enrichment Factor }=\frac{c_{e_{\text {sample }} / C_{\text {re_sample }}}}{c_{\text {e_ref }} / C_{\text {re_ref }}}
$$

Ce_sample is the concentration of the element in the sample, Cre_sample is the concentration of the reference element in the sample, Ce_ref is the concentration of the element in the reference material, and Cre_ref is the concentration of reference element in the reference material.

Dust is mainly originated from surface soil. In the atmospheric storms, dust enters into the atmosphere through erosion of soil, and the elements in the dust are enriched by absorbing the atmos-

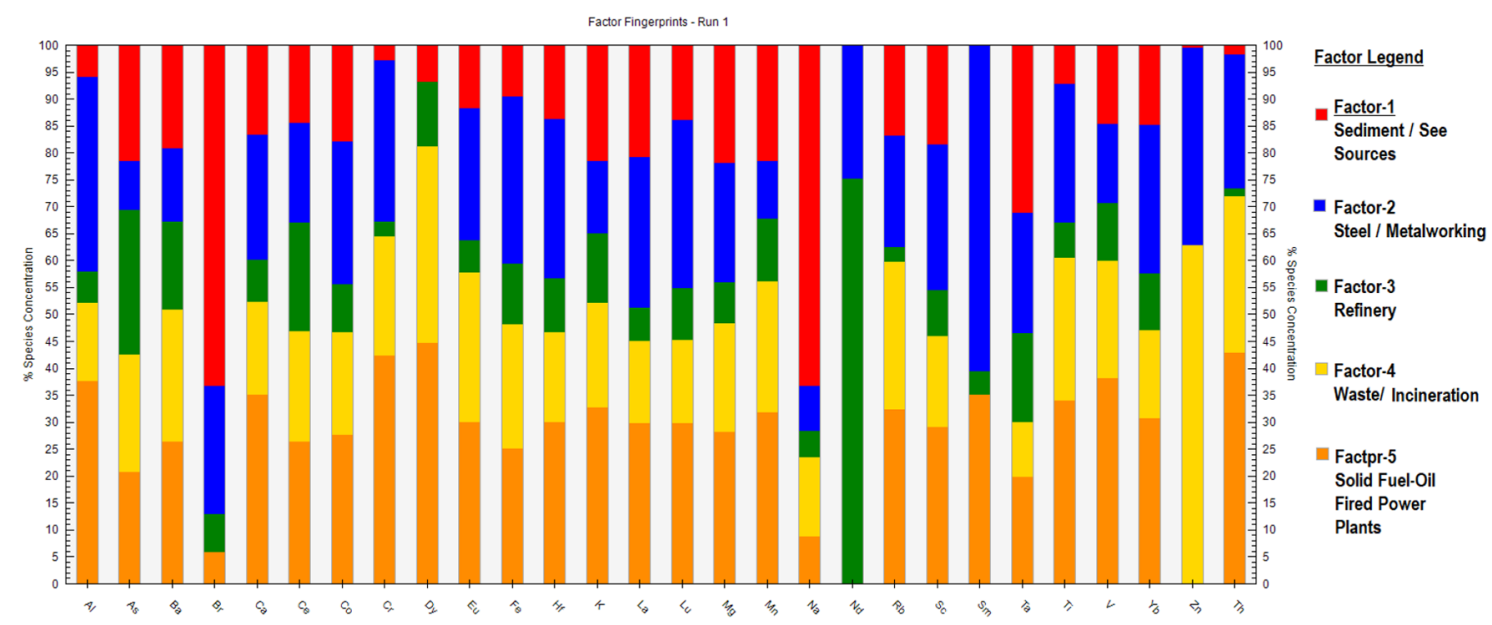

Fig. 3. Factors Produced from PMF Modeling. 
pheric pollutions. For EF calculation, mainly one of the major elements in the soil such as Sc, Fe, Al, Ti, and $\mathrm{Mn}$ is selected as the reference element; the reason is the low mobility of these elements [21-25]. In this study, the soil is used as the reference material [19] and Sc as a reference element for the calculation.

\section{Results and Discussion}

\subsection{Investigation of Factors Obtained from PMF Modeling for Dust samples}

Table 1, 2 and 3 indicates the summary of data and the results obtained; the rows one to four present the summaries of some synoptic data on the dust event days. The fifth row indicates the important factors obtained from the implementing of PMF Modeling for each of the samples. The sixth row refers to possible pollutant sources related to each factor. The results of PMF Modeling show five factors. These factors indicate to the five pollutant sources including sedimentary surface soil / dried bed of wetlands 2) Steel/ Metalworking 3) Refinery 4) Waste 5) Solid Fuel/ Oil-fired power plants. Each factor includes a group of elements with maximum correlation; this correlation indicates a probable source according to Table S3 [27-44]. The seventh row indicates the pollutant sources located around the sampling site. The last row shows the external

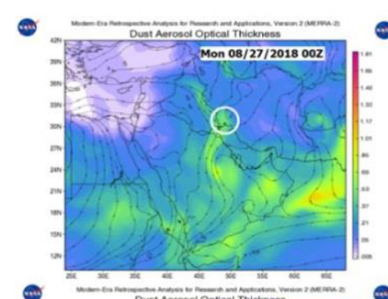

‥
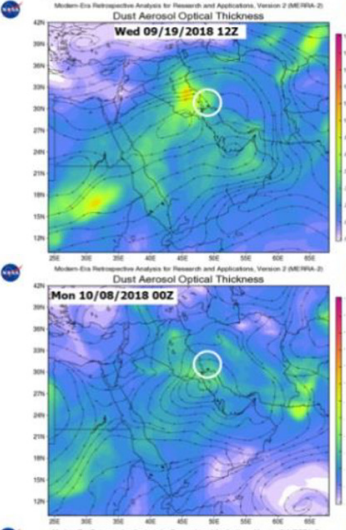

-

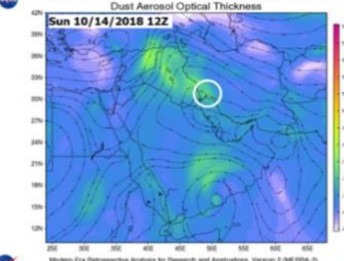

-
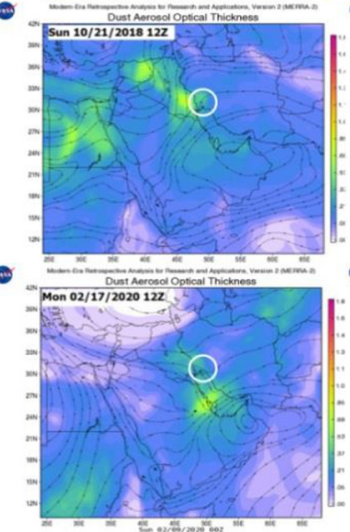
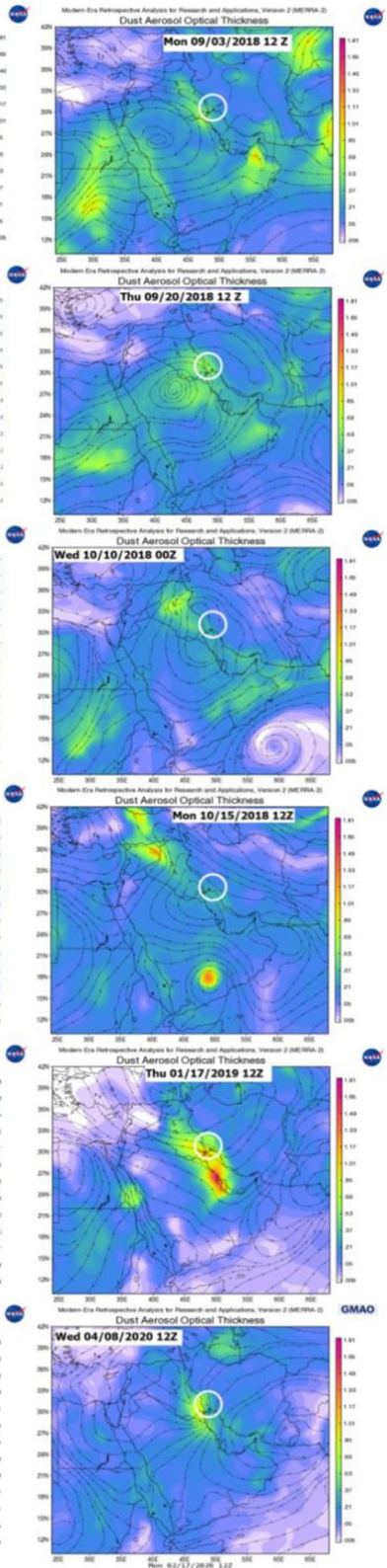

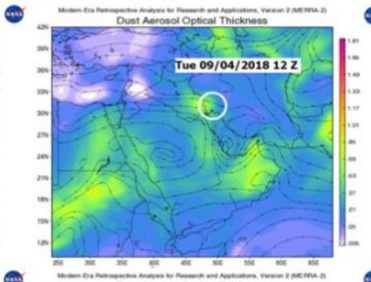

-
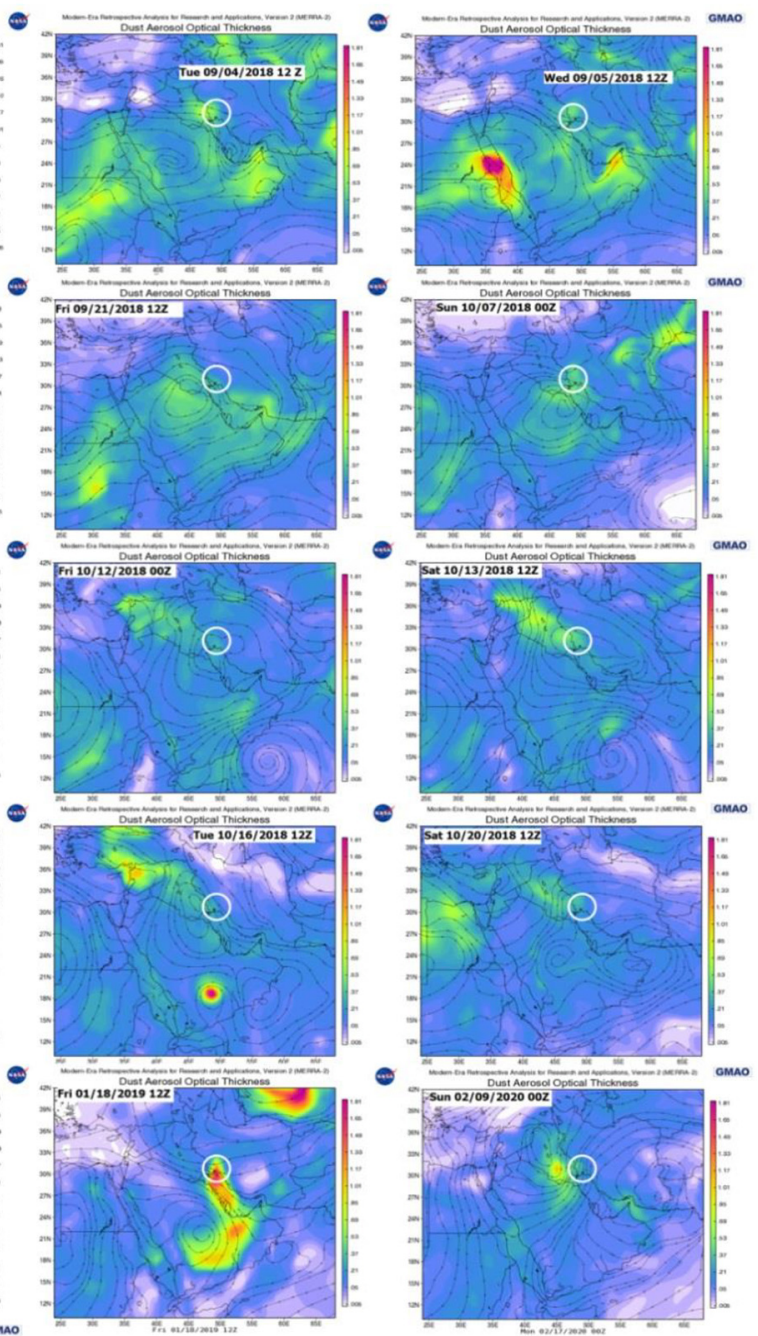

Fig. 4. NASA's infrared images of dust events in the Middle East based on AOT, on sample collection dates, polygons show the study area [45]. 


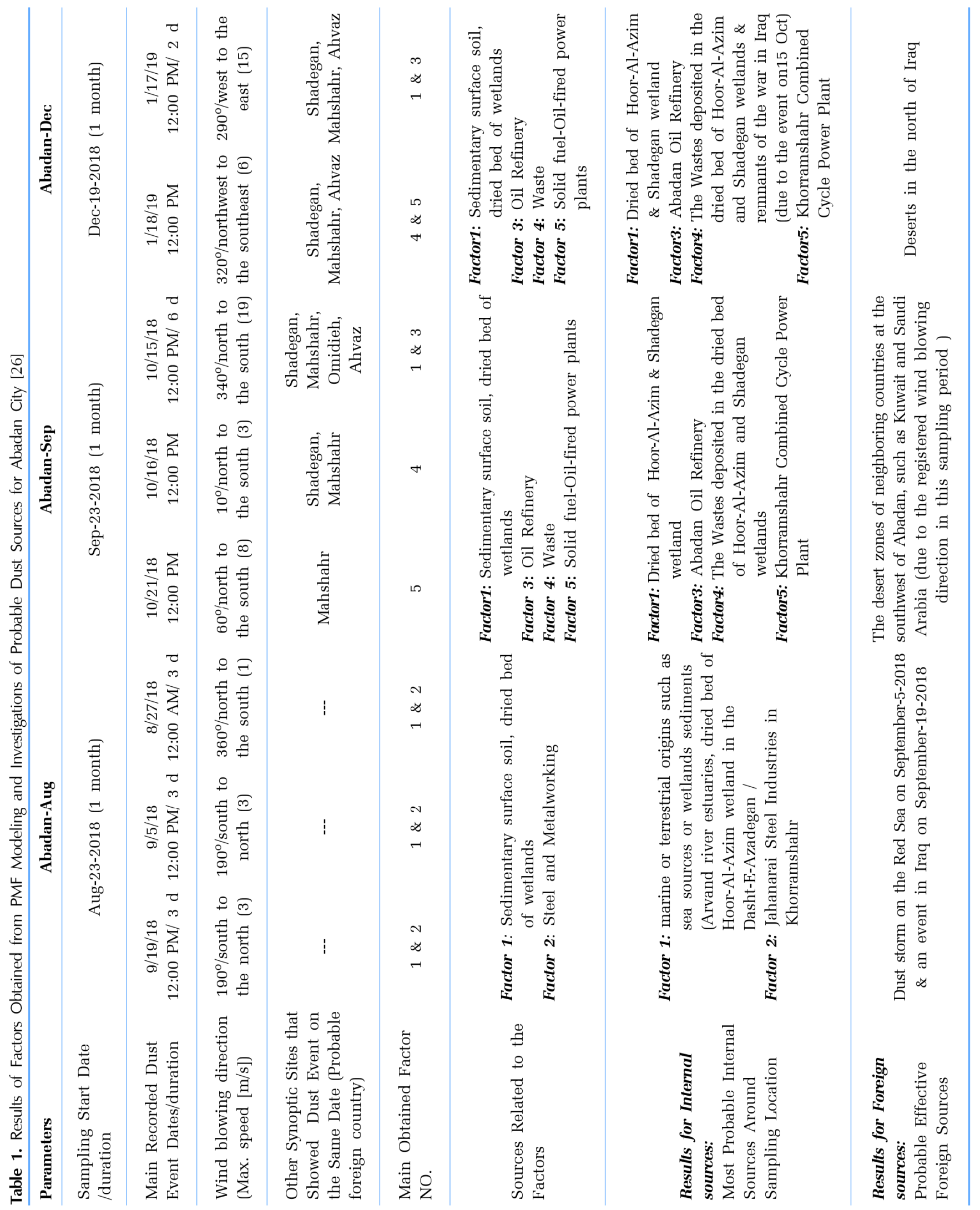




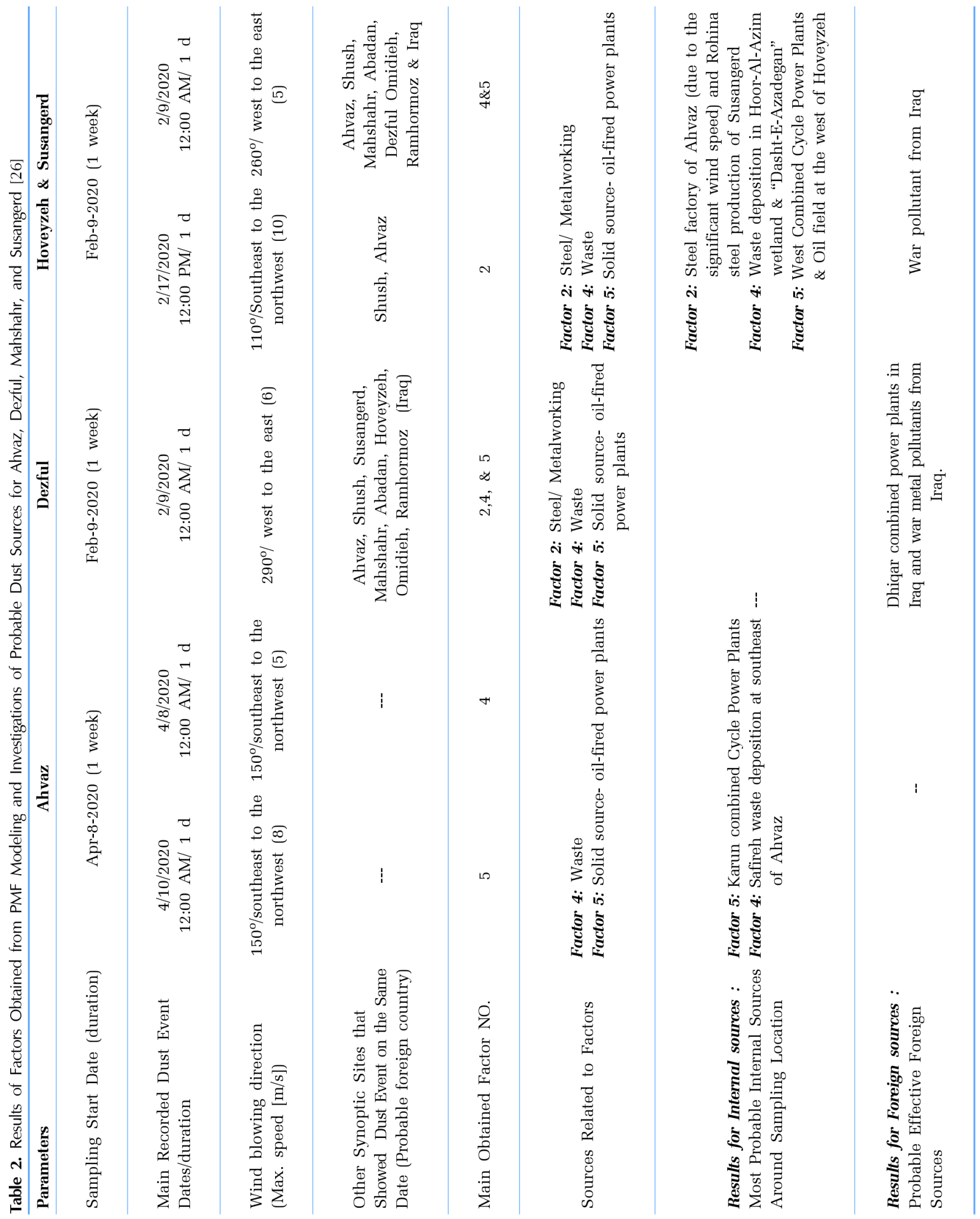




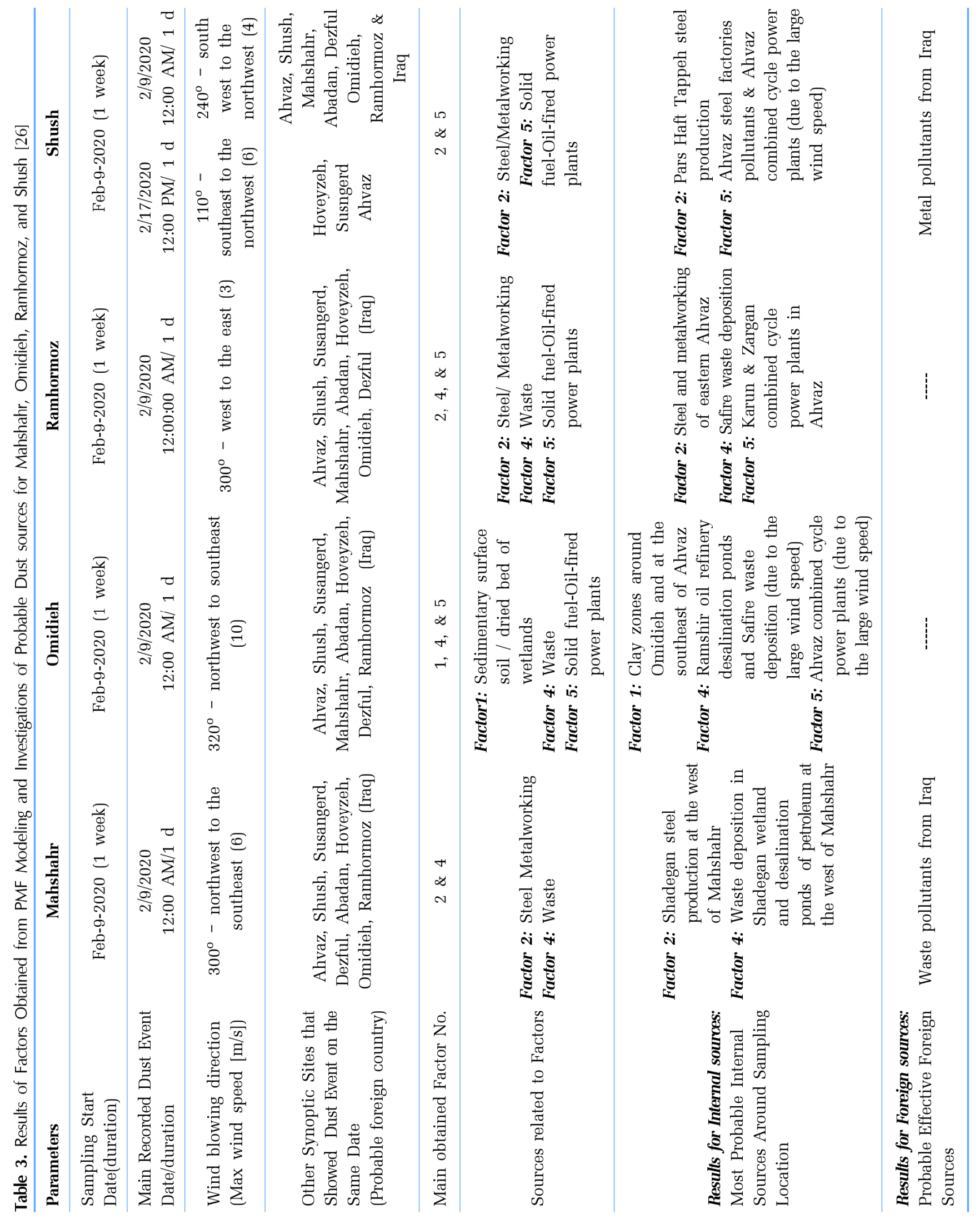




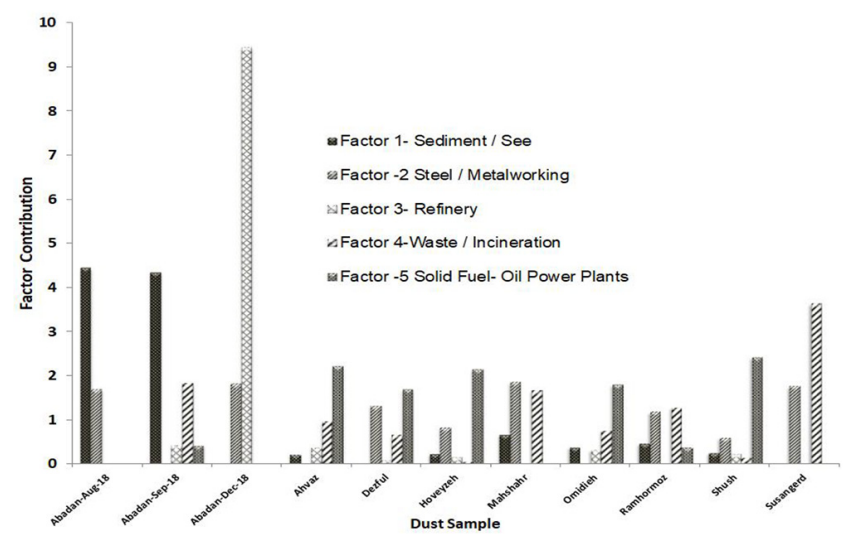

Fig. 5. Normalized contribution of factors in dust samples.

dust events according to the NASA AOT images [45] in Fig. 4. Fig. 5 presents the concentration of factors in each sample summarized in (Table 1, 2, and 3).

\subsection{Investigation of Enrichment Factors and Correlation Coefficients}

Table S4 presents the calculated EF values for elemental concentrations in the dust samples. The quantities larger than 1 indicates the enrichment of elements because of pollutant sources. Fig. S1 shows the correlations among the chemical elements in the dust samples (Table S1) [22, 46, 47]. This quantity is divided into four categories [48]. Correlation coefficients greater than 0.8 are very strong. Those between 0.6 and 0.8 are considered strong. Those between 0.4 and 0.6 are considered moderate and those below 0.4 are considered weak. Strong correlations among the elements in a category indicate the dependence of those elements on a single source [49, 50], especially if they have high enrichment factors.

In Fig. S1, As and Se have a strong correlation with the elements $\mathrm{Ce}$ and $\mathrm{Nd}$; $\mathrm{Nd}$ and Ce are among the rare earth elements whose most important production sources are oil and refining industries. Rare earth and As, usually belong to fossil fuel combustion pollutants especially combined fuel power plants with mazut fuel (Table S3). In the samples of Ahvaz, Shush, Susangerd, and Hoveyzeh, a strong correlation among these elements indicates to the mentioned pollution sources. For example in the dust event of February-17-2020 (Table 2) in these cities, according to the wind blowing direction, southeast to the northeast, the Karoon cycle power plant in Ahvaz city could have been pollutant sources for those samples. The great EF values for the mentioned correlated elements in Table S4, such as As, Se and rare earths confirm this result.

In samples such as Abadan-Aug (Fig. S1), there is a strong correlation among $\mathrm{Br}, \mathrm{La}, \mathrm{Mg}, \mathrm{Na}$, $\mathrm{Ta}$, and $\mathrm{Ca}$; as can be seen from the composition of the elements, the presence of terrestrial, sediment, and marine sources are well evident (Table S3). $\mathrm{Na}$ and $\mathrm{Br}$ are correlated to each other, and are belonged mainly to the salt compounds that are derived from the sea or the dried bed of lakes or wetlands. In this sample, for example, in the event of August-27-2019 (Table 1), according to the wind blowing direction, north to south, "Dasht-E-Azadegan" and, Hoor-Al-Azim dried wet- land bed and Arvand river estuaries and mud-salt zones or areas with fine sediments and evaporitic deposits could have been pollutant sources for this sample. The great EF values of most of the mentioned correlated elements in Table S4 for this city, such as $\mathrm{Na}, \mathrm{Br}, \mathrm{Ca}$, and $\mathrm{Mg}$, also confirm this result. In some samples such as Abadan-Aug, Ahvaz, Shush, Susangerd, and Hoveyzeh the elements such as Co, Hf, Lu, Mg, Mn, Sc, Ta, Yb, Fe, K, Na are strongly correlated with each other; most elements of this group are related to the sources of the metal and steel industries (Table S3). For the mentioned event of Abadan on August-27-2018, the Jahanarai steel industry is the most probable pollutant source. For other cities such as Ahvaz, Shush, Susangerd, and Hoveyzeh in the event of February-17 (Table 2), there are numerous metal and steel industries around Ahvaz, that according to the wind blowing condition and other data in Table 3 could have been pollutant sources for those samples. For Shush, the Pars Hafttappeh steel industry can be a pollutant source. The significant EF values of most of the correlated elements in this group (Table S4), such as $\mathrm{Fe}, \mathrm{Mn}, \mathrm{Co}, \mathrm{Cr}$, also confirm this result.

The rare earths such as $\mathrm{Ce}, \mathrm{Hf}, \mathrm{Yb}, \mathrm{Co}$, Lu are strongly correlated (Fig. S1). These elements are mainly used as catalysts in various industries such as oil and petrochemical industries and refineries (Table S3). Eu and $\mathrm{Zn}$ also show strong correlations; Eu is mainly dependent on the earth's crust, $\mathrm{Zn}$ is dependent on waste, and in general, the correlation between the two can indicate the source of accumulation of waste in the bed of wetlands and rivers [51-60].

For Ahvaz and Susangerd samples in Table S4, the EF value of $\mathrm{Zn}$ is significant. For Ahvaz in February-17-2020 (Table 2), Safireh waste deposition around this city, and for Susangerd deposition of waste in "Dasht-E-Azadegan" are the main waste sources.

\subsection{Identification of Dust Sources in Khuzestan Province}

The main goal of this study is recognition of the probable sources of dust events in Khuzestan province. In this regard, both internal and external sources of dust have to be identified. For investigation of internal sources, we have to consider the point mentioned in the introduction, that most of Khuzestan plain has been covered with surface sediments, of which about 30 to $35 \%$ are particles with the size of clay. This kind of soil is skillful of arising from the surface in the atmospheric currents. The origins of the dust can be different in different seasons of the year [20-25, 46-48]. In the following, we will briefly describe the dust events in this region in different seasons. Altogether, for identification of the sources, the data such as wind direction, duration of the events, the extent of the event in the study area, the number of cities involved in the same event, and the factors obtained for each sample are essential (Table 1,2 and 3).

\subsubsection{Internal sources}

On August-27-2018, synoptic data in Table 1 shows the direction of the wind blowing from north to south. On the other hand, the duration of dust was only one day, and the wind speed was low [61]. In addition, no event was recorded in any of the neighboring cities of Abadan in the study area, and the extent of the event was limited. This condition indicates that on this date, which coincides with the last month of summer, the source of dust was local. The obtained factors and their related internal pollutant sour- 
ces can be strong indicators for the internal origin of this dust event; because these found pollutant sources are precisely located around the sampling location or in the route of dust movement to the sampling locations. Factor 1 for this event can indicate the dried wetlands or sedimentary lands such as Arvand river estuaries, mud-salt zones, or areas with fine sediments with evaporitic deposits and "Dasht-E-Azadegan," in the north of Abadan. Factor 2 for this event can be related to the Jahanarai Steel Industries in Khorramshahr that is the primary internal pollutant source near Abadan in the study area.

The event that happened on February-17-2020 is limited only to Ahvaz, Shush, Susangerd, and Hoveyzeh. The direction of the wind blowing was from southeast to northwest. According to Fig. 1 and Fig. 2, in this direction, there are dried sedimentary plains in the east and southeast of Ahvaz and plains between Omidieh and Mahshahr. It seems that the atmospheric currents from the Persian Gulf have been able to move the dust from the mentioned areas. For this event, according to Table 3, factors 2 and 5 are the main factors obtained. In the route of atmospheric current and around the involving cities, there are steel and metalworking industries such as Pars Hafttappeh and Ahvaz steel industries. For factor 5, there is the Karoon combined cycle power plant in Ahvaz. Therefore, it can be concluded that in mid-winter, the winds that blow from the east, southeast, and the Persian Gulf, cause the rising of dust from the sedimentary plains in Fig. 2; so in these events, the source of dust is mainly internal, and the extent of the event is limited [62-70].

For Ahvaz city in April, NASA image in Fig. 4 and synoptic data in Table 2 show the most dominant atmospheric current was from south and southeast (from the Persian Gulf). The extent of the event was limited to Ahvaz and, the duration was one day. It seems that, like the events during the mid-winter and the early autumn, the events that happened in early spring have internal origins. Factor five for this event is related to the Karoon combined cycle power plant of Ahvaz, and factor 4 is mainly related to Safireh waste deposition at the southeast of Ahvaz.

\subsubsection{External sources}

On September-5-2018 which coincides with early autumn, the recorded wind direction is from south to the north, and the wind speed is low. However, due to the three-day continuity of events, the role of external sources can be considered. For example, on this date, a significant dust event is seen on the Red Sea (Fig. 4), which could have been the source of dust for Abadan.

The event on September-19-2018 has been continued up to the next two days, and the direction of the wind changed from northwest to the southeast. On this date, a dust event has been recorded in Iraq, which according to the wind direction and the three-day continuity of dust can be an external source for the event in Abadan (Fig. 4). Therefore, the events with a low wind speed and long duration that cover a large extent area, most probably have an external source.

Another important example is the event on October-15-2018; the assessment of NASA images in Fig. 4 shows that on October-15 and 16, two significant dust events occurred, one in northern Iraq and the other in Saudi Arabia. This event lasted for six days, which is a very long time, and the wind speed on October-15 was relatively high. Another point is that some other cities including Mahshahr, Shadegan, Omidieh, and Ahvaz simultaneously experienced dust events as Abadan. In general, in this event, northern Iraq could have been a significant source of dust in the city of Abadan.

NASA AOT images show an event on January-17-2019 in Iraq. The Figure shows that this event has been going in the southeast direction and continued on the eighteenth day. During these dates, almost all the cities in the study area were affected by dust. The wind speed was high on January-17. It seems that according to the mentioned points, the event that took place in Iraq is the primary source of the dust event in Abadan and other cities in the study area of Khuzestan.

In the event that happened on February-9-2020, according to the data in Table 2 and 3, almost all the cities in the sampling area were involved in the dust. The duration of the event was one day. The speed and direction of the wind are almost the same in all the cities. It can be concluded that a unit event occurred with a single origin. A cross-border source can be a good option for the analysis of this event. NASA image on this day shows an event occurring in Iraq.

Therefore, according to the explained cases, it can be concluded that most of the dust events that happened in mid-autumn to early winter had mainly foreign origins, especially those with a long duration.

\section{Conclusions}

In this study, the probable sources of dust events in Khuzestan province in different seasons were investigated. For the first time, a comprehensive dust sampling was performed in the four seasons and nine cities throughout the wide study area.

Investigation of the dust events and synoptic data showed that for the dust events at the end of the summer up to the early autumn and the mid-winter up to the early spring, internal origins are more dominant. In these cases, the extent of the events was limited to one city or a few cities around the sampling location, and the duration of the events was just one day. For these events, three factors were obtained from PMF Modeling that were relevant to the local pollutant sources around the sampling locations, confirming the internal origin of the dust events. The significant EF values of the correlated chemical elements of the dust sample also confirm this result. One of these pollutant sources was related to the sedimentary and dried grounds that include Arvand river estuaries and mud-salt zones or areas with fine sediments with evaporitic deposits and puffy grounds in the regions between Omidieh-Mahshahr, south, and southeast of Ahvaz and "Dasht-E-Azadegan," at the north of Abadan.

The other pollutant source was related to steel and metalworking. This source includes Jahanarai Steel industries in Khorramshahr, above the Abadan, and the steel factories in Ahvaz and Pars Hafttapeh; and the last pollutant source was related to the solid/oil-fired power plants which involves the combined cycle power plant of Karoon in Ahvaz as the primary example for this pollutant source.

Those events that have taken place from the mid-autumn up 
to the early winter are of external origins. The meteorological data showed that in most of these events, the duration of the events is long, the extent of the event in the study area was considerable, and most of the cities in the region were involved in the event. During these events, we witnessed dust events in the neighboring countries in NASA AOT images; prominent examples were the events in Iraq, the Red sea, Saudi Arabia, which undoubtedly have been the external sources for the events in Khuzestan on the corresponding dates.

In this study, due to the large number of rainy days in the investigated area during the spring, no sample was collected from the middle up to the end of spring. However, since the end of spring is the most critical time for the emergence of dust events in the southwest of Iran, a comprehensive sampling in the area similar to the one conducted in this research work is strongly recommended during this period to identify the main dust sources, especially those of external origins.

\section{Acknowledgment}

We are very grateful to all the colleagues of the Geological Survey of Iran for their efforts in sample collection.

\section{Author Contributions}

Z.A. (Ph.D. student) conducted all the experiments and wrote the manuscript. O.K. (Professor) revised the manuscript. R.S. (Associate Professor) revised the manuscript. J.D.K. (Associate Professor) performed the sample collection. M.M. (Associate Professor) performed the sample collection

\section{References}

1. Reza BK, Bubak S. Evaluation of heavy metal contamination hazards in nuisance dust particles, in Kurdistan Province, western Iran. J. Environ. Sci. 2013;25(7):1346-1354.

2. Zhang J, Zhang Q, Tang C, Han Y, Aerosol structure and vertical distribution in a multi-source dust region, J. Environ. Sci. 2012;248:1466-1475.

3. Hesam S, H, Reza K, Mohsen S. Transport routes and potential source regions of the Middle Eastern dust over Ahvaz during 2005-2017. Atmos. Res. 2020;241(2):104947.

4. Parya B, Ferhat K, Mert G,Arman F, Xueyu G, Jong RK. Destinations frequently impacted by dust storms originating from southwest Iran. Atmos. Res. 2021;248:105246.

5. Kaveh M, Maurizio S, Dimitrise GK. Classification of weather clusters over the Middle East associated with high atmospheric dust-AODs in West Iran. Atmos. Res. 2021;259:105682.

6. Mohamed FY, Sarah KA, Ali AH. Dust storms backward Trajectories and source identification over Kuwait. Atmos. Res. 2018;212:158-171.

7. Yanqin R, Jie W, Zhenhai W. Chemical components and source identification of $\mathrm{PM}_{2.5}$ in non-heating season in Beijing: The influences of biomass burning and dust. Atmos. Res.
2020;251:105412.

8. Peyman H, Ali A, Mohammad J, Javad DK, Somaye FF. Integrating remote sensing, GIS, and sedimentology techniques for identifying dust storm sources: A case study in Khuzestan, Iran. J. Indian Soc. Remote. Sens. 2018;46(1):1113-1124.

9. Mehdi M, Mohammad M, Alireza H, Maria C, Saeid B, Morteza AK. Khuzestan dust phenomenon: a content analysis of most widely circulated newspapers. Environ. Sci. Pollut. Res. 2018;25:15918-15924.

10. Hui C, Jian L, Guizhou W, Guang Y, Lei L. Identification of sand and dust storm source areas in Iran. J Arid Land. 2015;7(5): 567-578.

11. Mansour AF, Christian O, Michael G. Investigation of aeolian dust deposition rates in different climate zones of southwestern Iran. Atmosphere 2021;12(2):229.

12. Haim K, Hadar F. Dust storms in the Middle East: Sources of origin and Their temporal characteristics. Indoor Built. Environ. 2003;12:419-426.

13. Ismael DSA, Rebecca MB, Stefan E. Drought severity and increased dust storm frequency in the Middle East: a case study from the Tigris Euphrates alluvial plain, central Iraq. Weather 2019;74:416-426.

14. Zohra B, Mohammed M, Tarek A, et al. Investigation of aerosol trace element concentrations nearby Algiers for environmental monitoring using instrumental neutron activation analysis research. Atmos. Res. 2015;166:49-59.

15. Lylia H, Hocine S, Trik A, Boussaad Z. Concepts, Instrumentation and Techniques of Neutron Activation Analysis. Imaging and Radioanalytical Techniques in Interdisciplinary Research - Fundamentals and Cutting Edge Applications. In: Faycal Kharfi ed. IntechOpen; 2013. p. 141-178.

16. Chrysoula B, Evangelia D, Evdoxia T, et al. First-time source apportionment analysis of deposited particulate matter from a moss biomonitoring study in northern Greece. Atmosphere 2021;12(2):208.

17. Olga VS, Konstantin PK, Vladimir BB, et al. Multi-elemental characterization of the atmospheric aerosols in frames of inter laboratory experiment. Atmos. Res. 1998;46:349-359.

18. EPA United State Protection Agency. EPA 5.0 Positive Matrix Factorization for environmental data analyses [Internet]. Carlton: EPA Victoria; c2018 [cited 1 Feb 2018]. Avaiable from: https://www.epa.gov/sites/default/files/2015-03/epa_pmf_5.0_ setup.exe.

19. Barbieri M. The Importance of Enrichment Factor (EF) and Geoaccumulation Index (Igeo) to Evaluate the Soil Contamination. J. Geol. Geophys. 2016;5(1):1000237.

20. Zoller WH, Gladney ES, Duce RA. Atmospheric Concentrations and Sources of trace Metals at the South Pole. Science 1974;183(4121):198-200.

21. Fang GCh, Wu YS, Chang SY, Huang SH, Rau JY. Size Distributions of Ambient Air Particles and Enrichment Factor Analyses of Metallic Elements Taichung Harbor near the Taiwan Strait. Atmos. Res. 2006;81(4):320-333

22. KANTOR P, ŠVÉDOVÁ B, DROZDOVÁ J, et al. Comparison of Enrichment Factors for Heavy Metals in Urban Street Dust and Air Aerosols. J. Pol. Miner. Eng. Soc. 2018;19(1):209-216. 23. Dytłow S, Kostrubiec BG. Concentration of Heavy Metals in 
Street dust: an Implication of Using Different Geochemical Background Data in Estimating the Level of Heavy Metal Pollution. Environ. Geochem. Health 2021;43:521-535.

24. International Atomic Energy Agency. Sampling and Analytical Methodologies for Instrumental Neutron Activation Analysis of Airborne Particulate Matter, Training Course Series, 1992. Vienna: IAEA; 1992. p. 7-56.

25. Reimann C, Garrett RG, Geochemical Background-Concept and Reality. Sci. Total Environ. 2005;350(1-3):12-27.

26. Metrological Data. Metrological Organization of Iran [Internet]. c2030 [cited 1 July 2020]. Available from: https://www.irimo.ir/eng/wd/720-Products-Services.html.

27. Yassir A, Jamaâ D, Ali A, Khalid K, Hezhong T, Mohamed $\mathrm{H}$. Assessment of heavy metals released into the air from the cement kilns co-burning waste: Case of Oujda cement manufacturing (Northeast Morocco). Sustain. Environ. Res. 2018;28(6):363-373.

28. Ruud M. Trace element behavior in coal-fired power plants. Fuel Process. Technol. 1994;39:199-217.

29. Atiku FA, Ikeh PO, Faruk AU, Itodol AU, Abdulhamid A, Rikoto II. Comparative Test Analysis of Petroleum (Diesel and Gasoline) Soots as Potential Sources of Toxic Metals from Exhausts of Power Plants. Arch. Appl. Sci. Res. 2011;3(4):147-156.

30. Aixa G, Rodrigo N, Natalia M. Fly ashes from coal and petroleum coke combustion: current and innovative potential applications. Waste Manag Res. 2009;27:976-987.

31. Joseph AC, Kezhong Z, Nicholas JS, Benjamin MC, Shawn PME. Petroleum Coke in the Urban Environment: A Review of Potential Health Effects. Int. J. Environ. Res. Public Health. 2015;12:6218-6123.

32. Karzan MK. Correlation between air quality and wastewater pollution. Environmental Sustainability - Preparing for Tomorrow. In: Syed Abdul Rehman Khan ed. IntecOpen; 2021. 95582.

33. Elena H, Blagorodka V, Emilia G, Hristomir B. Application of positive matrix factorization receptor model for source identification of PM10 in the city of Sofia, Bulgaria. Atmosphere 2020;11(9):890.

34. Jean FF, Nathalie S, Jean FG, Pierre CM, Urs S. Elemental characterization and source identification of $\mathrm{PM}_{2.5}$ using Positive Matrix Factorization: The Malraux road tunnel, Nice, France. Atmos. Res. 2009;94(2):320-329.

35. Jong ML, Jin HL, Jong HM, Yong SC, Ki HK. Source apportionment of PM10 at a small industrial area using Positive Matrix Factorization. Atmos. Res. 2010;95:88-100.

36. Eugene K, Timothy VL, Philip KH, et al. Source identification of PM2.5 in an arid Northwest U.S. City by positive matrix factorization. Atmos. Res. 2003; 66(4):291-305

37. Suwei Z, Qijie Z, Armand A, et al. Particulate matter pollution in Kunshan High-Tech zone: Source apportionment with trace elements, plume evolution and its monitoring. J. Environ. Sci. 2018;71:119-126.

38. Mengtian C, Guiqian T, Bo L, et al. Source apportionment of $\mathrm{PM}_{2.5}$ and visibility in Jinan, China. J. Environ. Sci. 2021;102: 207-215.

39. Guangxuan Y, Puzhen Z, Jie Y, et al. Chemical characteristics and source apportionment of $\mathrm{PM}_{2.5}$ in a petrochemical city:
Implications for primary and secondary carbonaceous component. J. Environ. Sci. 2021;103:322-335.

40. Mohsen S, Nasibeh A, Babak S, Dongsheng W, Liping F. Heavy metals and their source identification in particulate matter $\left(\mathrm{PM}_{2.5}\right)$ in Isfahan City, Iran. J. Environ. Sci. 2018;72:166-175.

41. Kazi KN, Sudip KPal , Shahadat H, Ahasanul K. Evaluation of heavy metal pollution risk associated with road sediment. Environ. Eng. Res. 2021;26(3):200239.

42. Kyung MB, Young KS, Jun YK, Sung OB. Monitoring of particulate hazardous air pollutants and affecting factors in the largest industrial area in South Korea: The Sihwa-Banwol complex. Environ. Eng. Res. 2020;25(6):908-923.

43. Deepak P, Jeong HK, Sang HL, Sung JC, Geum JS, Yong CS. Hazardous Air Pollutants Emission Characteristics from Cement Kilns Co-burning Wastes. Environ. Eng. Res. 2009;14(4):212-219.

44. Meshari AH, Abdulrahman AM, Asma A. Spatiotemporal variations and source apportionment of NOx, SO2, and $\mathrm{O} 3$ emissions around heavily industrial locality. Environ. Eng. Res. 2020;25(2):147-162.

45. NASA Global Modeling and Assimilation Office (GMAO) [Internet]. c2020 [cited March 15 2020]. Available from: https://fluid.nccs.nasa.gov/reanalysis/chem2d_merra2/.

46. Brady JP, Ayoko GA, Martens WN, Goonetilleke A. Development of a hybrid pollution index for heavy metals in marine and estuarine sediments. Environ. Monit. Assess. 2015;187(5):306.

47. Fang GC, Cheng Chen Y, Jhy Lee W, et al. A review of atmospheric fine particulate matter and its associated trace metal pollutants in Asian countries during the period 1995-2005. J. Hazard. Matter. 2007;143:511-515.

48. Akoglu H. User's Guide to Correlation Coefficients. Turk. J. Emerg. Med. 2018;18(3):91-93.

49. Ramos SJ, Dinali GS, Oliveira C. Rare Earth Elements in the Soil Environment. Curr. Pollut. Rep. 2016;2:28-50.

50. Edahbi M, Plante B, Benzaazoua M, Kormos L, Pelletier M. Rare Earth Elements (La, Ce, Pr, Nd, and Sm) from a Carbonatite Deposit: Mineralogical Characterization and Geochemical Behavior. Minerals 2018;8(2):55.

51. Arfala Y, Douch J, Assabbane A. Assessment of Heavy Metals Released into the Air from the Cement Kilns Co-Burning Waste: Case of Oujda Cement Manufacturing (Northeast Morocco). Sustain. Environ. Res. 2018;28:363-373.

52. Meij R. Trace Element Behavior in Coal-Fired Power Plants, Fuel Process. Technol. 1994;30(1-3):199-217.

53. Atiku FA, Ikeh PO, Faruk UZ. Comparative Test Analysis of Petroleum (Diesel and Gasoline) Soots as Potential Sources of Toxic Metals from Exhausts of Power Plants, Scholars Research Library. Arch. Appl. Sci. Res. 2011;3(4):147-156.

54. Caruso JA, Zhang K, Schroeck NJ, McCoy B, McElmurry SP. Petroleum Coke in the Urban Environment: A Review of Potential Health Effects. Int. J. Environ. Res. Public Health 2015;12(6):6218-6231.

55. Dung TTT, Vassilieva E, Swennen R, Cappuyns V. Release of Trace Elements from Bottom Ash from Hazardous Waste Incinerators. Recycling 2018;3:36.

56. Font A, Hoogh K, Sanchez ML, et al. Using Metal Ratios to Detect Emissions from Municipal Waste Incinerators in Ambient Air Pollution Data, Atmos. Environ. 2015;113:177-186. 
57. Clarke LB. The Fate of Trace Elements During Coal Combustion and Gasification: an Overview. Fuel 1993;72(6):731-736.

58. Dai QL, Bi XH, Wu JH, et al. Characterization and Source Identification of Heavy Metals in Ambient PM10 and PM2.5 in an Integrated Iron and Steel Industry Zone Compared with a Background Site. $A A Q R$ 2015;15:875-887.

59. González A, Navia R, Monero N. Fly Ashes from Coal and Petroleum Coke Combustion: Current and Innovative Potential Applications. Waste Manag. Res. 2009;27:976-987.

60. Ahrens LH. Origin and Distribution of the Elements. In: 1th ed. International Series of Monographs in Earth Sciences. Pergamon Press; 1968. p. 1165-1178.

61. Classification of Wind Speed [Internet]. c2020 [cited 23 Oct 2020]. Available from: https://www.windows2universe.org/ earth/Atmosphere/wind_speeds.html.

62. Alireza K, Chenglai W, Zhaohui L. Interannual variations of dust activity in western Iran and their possible mechanisms. Big Earth Data. 2020;4(2):175-190.

63. Dargahian F, Lotfinasabasl S, Khosroshahi M. Analysis of the role of internal dust sources in creating critical conditions in Ahvaz with an emphasis on the southeastern area. Forest Range Protect. Res. 2019;16(2):157-170.

64. Malamiri N, Rashki A, Hosseinzadeh S, Gahadi Toroqh M.
Identification of Desert Dust Sources in the West Khuzestan Province using of Brightness Temperature Algorithms. J. Geog. Env. Haz. 2019;8(3):97-110.

65. Abbasali DR, Mahmoud A, Alireza. Seasonal Study of Dust Deposition and Fine Particles (PM 2.5) in Iran Using MERRA-2 Data. Indian J. Geophysics 2020;43-59.

66. Dadashi-Roudbari A, Ahmadi M. An assessment of change point and trend of diurnal variation of dust storms in Iran: a multi-instrumental approach from in situ, multi-satellite, and reanalysis dust product. Meteorol. Atmos. Phys. 2021;133:1523-1544.

67. Mansour A, Parviz R. Study of Mineralogy and Geochemistry of Dust Storms in the Khuzestan Province (Case Study of Dezful City). Environ Res. 2019;10(19):301-0311.

68. Aliakbar N, Ziaoddin S. Identifying Areas with Dust Generation Potential in the West of Iran, Case Study: Khuzestan Province. J. Watershed Manag. Res. 2018;10(3):398-409.

69. Khatooni J, SARA N, Foroogh A, et al. Composition and Source of Dust Entering Khuzestan Province from an External Origin. Environ. Sci. 2017;15(2):93-110.

70. Hui C, Jian L, Guizhou W, Yang G, Lei L. Identification of sand and dust storm source areas in Iran. J. Arid Land. 2015;7(5):567-578. 